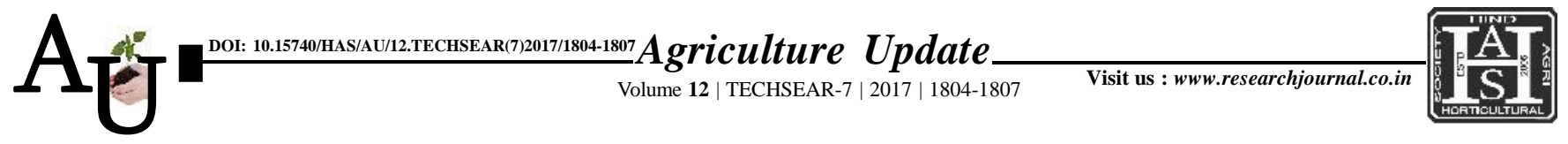

\title{
Research article: Species diversity and richness among tribal homesteads of the Nilgiris district of Tamil Nadu
}

\section{R. RAJASEKARAN, K. INDUMATHY AND N. KALIDASS}

Article Chronicle: Received : 19.07.2017; Accepted : 03.08.2017

KEY WoRDS : Agrobiodiversity, Tribal homestead, Species richness, Diversity

Author for correspondence :

\section{R. RAJASEKARAN}

Department Agricultural Extension, Don Bosco Agricultural College, Arakkonam, VELLORE (T.N.) INDIA

See end of the article for authors' affiliations
SUMMARY : Agro-biodiversity in this study referred as, variety of components such as cereals and millets, vegetables, fruits, spices and condiments, plantation and livestock present in the tribal homesteads of The Nilgiris district. The study was conducted at tribal areas of Nilgiris district which is known as biodiversity hot spot. The list of tribal respondents from selected village was obtained from horticulture department. A sample size of 100 homesteads respondents were fixed for the study. The technique proportionate random sampling was followed for the selection of respondents from three habitations viz., kunjappanai, mantharai, thuthikarai. Two ecological indices were used to analyse the agro-biodiversity viz., Species diversity among tribal homesteads based on Shanon-Wiener index and species richness in tribal homesteads by using Margalef Index. Majority of the tribal homesteads had medium level of diversity and species richness. A participatory group approach is needed in the tribal areas to conserve agro-biodiversity.

How to cite this article : Rajasekaran, R., Indumathy, K. and Kalidass, N. (2017). Species diversity and richness among tribal homesteads of the Nilgiris district of Tamil Nadu. Agric. Update, 12(TECHSEAR-7) : 1804-1807; DOI: 10.15740/HAS/AU/12.TECHSEAR(7)2017/1804-1807. 